Article

\title{
Characterization of Polyorganosilazane-Derived Hybrid Coatings for the Corrosion Protection of Mild Steel in Chloride Solution
}

\author{
Michele Fedel ${ }^{1}$, Francisco Javier Rodríguez Gómez ${ }^{2}{ }^{\circledR}$, Stefano Rossi ${ }^{1}[\mathbb{C}$ \\ and Flavio Deflorian 1,*D \\ 1 Department of Industrial Engineering, University of Trento, Via Sommarive n. 9, 38123 Trento, Italy; \\ michele.fedel@unitn.it (M.F.); stefano.rossi@unitn.it (S.R.) \\ 2 Departamento de Ingeniería Metalúrgica, Facultad de Química, Universidad Nacional Autonoma de Mexico, \\ Mexico City 04510, Mexico; fxavier@unam.mx \\ * Correspondence: flavio.deflorian@unitn.it
}

Received: 23 August 2019; Accepted: 17 October 2019; Published: 19 October 2019

\begin{abstract}
Polysilazane (PSZ) have been used for many years as precursors for the development of ceramic materials. Recently, hydrocarbon-substituted polysilazane, which is called organopolysilazane (OPSZ), has been proposed as possible alternative to silanes for the corrosion protection of metals by the sol gel route. In this work, polymethyl(hydro)/polydimethylsilazane-derived coatings were deposited on low-carbon steel for corrosion protection purposes. The effect of the OPSZ precursor concentration (10-40 $\mathrm{v} / \mathrm{v} \%$ ) in butyl-acetate on the final properties of the coatings was investigated. Coatings in the thickness range of 1 to $3.5 \mu \mathrm{m}$ were obtained. The experimental results showed that the concentration of OPSZ in the solvent affects the structural properties as well as the dry film thickness of the hybrid layer. In particular, the network arrangement seems to be influenced by the dilution of the OPSZ precursors solution. The electrochemical characterization revealed that a minimum thickness of about 2 to $3 \mu \mathrm{m}$ is needed to provide the mild steel substrate with enhanced corrosion protection properties compared to the bare substrate. Comparing the obtained results with literature data, it seems that OPSZs are a potential alternative to coatings derived from organisilicon precursors.
\end{abstract}

Keywords: polysilazanes; thin films; FT-IR; EIS; polarization curves

\section{Introduction}

Thin ceramic coatings have been extensively studied for the protection of steel against corrosion and degradation. These protective layers are commonly applied by means of different techniques: Vacuum technology (such as physical vapor deposition, PVD [1,2]; chemical vapor deposition, CVD [3,4]; and atomic layer deposition, ALD [5,6]), inductively coupled radio frequency plasma [7], and metal alkoxides-based sol-gel route [8-12]. As far as the latter deposition technique is concerned, silicon alkoxides, zirconium alkoxides, and titanium alkoxides have been extensively investigated for the development of hybrid films for the protection of different metals, in particular mild steel, stainless steel, zinc, aluminum, and magnesium. Among the different hybrid molecules that have been object of investigation, only very few literature reports deal with the use of polyorganosilazanes (OPSZs) [13-15] to develop protective films for the corrosion protection of low-carbon steel. OPSZ are polysilazanes (PSZs) in which hydrocarbon substituents are bound to silicon atoms. In this context, generally speaking, OPSZs have not been the subject of extensive research in the field of corrosion protection of metallic materials, as only a little investigation has been carried out $[16,17]$. Polyorganosilazanes (OPSZs) consist of a class of materials characterized by a Si-N-Si structural framework where silicon and nitrogen atoms are alternately connected. Reactive or inert side groups are bonded on the Si 
atoms $[18,19]$. In particular, along with hydrocarbon substituents, highly reactive Si-H and N-H are present in the OPSZ backbone, thus making these materials suitable to form a dense silica network as well as adherent films on diverse substrates. In fact, due to the high reactivity of the $\mathrm{Si}-\mathrm{N}, \mathrm{N}-\mathrm{H}$, and $\mathrm{Si}-\mathrm{H}$ bonds towards $\mathrm{OH}$ groups, OPSZs are recognized to be able to form Si-O-Me bonds $[20,21]$ on a metal surface thanks to the strong affinity with the metal hydroxides. It has been demonstrated that by means of thermal or chemical curing, highly crosslinked networks can be obtained (accompanied by the release of hydrogen and ammonia as by-products). In the last decades, these materials have been extensively used as precursors for the production of $\mathrm{SiO}_{2}, \mathrm{Si}_{x} \mathrm{~N}_{y}$, and $\mathrm{Si}_{x} \mathrm{C}_{y} \mathrm{~N}_{z}$ ceramics through high-temperature thermal decomposition of the polymer in inert or reactive atmospheres [22-26] or by exposure to reactive species, such as ammonia [27] or boron chloride [28]. However, OPSZs are moisture curable polymers [29], which can also be used for the production of ceramic or hybrid materials by a relatively low-temperature heat treatment $\left(<240^{\circ} \mathrm{C}\right)[18,19,30-32]$. Under such curing conditions, the obtained materials are recognized to combine good barrier properties and mechanical strength [33]. As far as carbon steel is concerned as the substrate to coat, analogously to the hybrid organic-inorganic coatings derived from metal alkoxides precursors, OPSZs have potential as a metal pre-treatment prior to painting or as a standalone protection system for mild environments. Although this class of materials is not new and is already commercially available, novel alkoxysilyl-substituted polysilazane recently attracted considerable interest [34]. In addition, to the best of our knowledge, an electrochemical assessment of the corrosion protection properties of OPSZ films deposited on mild steel has not been carried out yet. For this reason, in this work, an OPSZ, namely propyltriethoxysilyl-substituted polymethyl(hydro)/polydimethylsilazane (PMDMS), has been employed to develop hybrid coatings for the corrosion protection of mild steel. In previous works by the same authors, OPSZ was employed to develop hybrid films on 1050 aluminum alloy [35,36]. By investigating the curing parameter (time and temperature) and the concentration of the precursor it was possible to obtain protective films that enhanced the durability of the substrate. Aiming to assess the potential of this material to develop protective coatings on mild steel, in this work, different dilutions of the OPSZ in butyl-acetate were the object of investigation. The hydrolysis of the S-H and S-N was carried out under controlled conditions by exposing the samples in the climatic chamber at $80 \%$ R.H. during $24 \mathrm{~h}$. The chemical-structural changes induced by the curing procedure were assessed by means of FT-IR spectroscopy. The corrosion protection properties were evaluated by means of electrochemical techniques, such as electrochemical impedance spectroscopy (EIS) and polarization curves collected in $0.1 \mathrm{M} \mathrm{NaCl}$ solution. A scanning electron microscope (SEM) was employed to measure the dry film thickness and an optical microscope $(\mathrm{OM})$ was used to evaluate the condition of the surfaces after exposure to $0.1 \mathrm{M} \mathrm{NaCl}$.

\section{Materials and Methods}

Standard matt finish Q-Panel steel $(\mathrm{C}<0.15, \mathrm{Mn}<0.60, \mathrm{P}<0.03, \mathrm{~S}<0.035$, Fe bal.) was used as the substrate to coat. Prior to coating, the substrates were degreased in acetone under ultrasounds for $6 \mathrm{~min}$. A commercially available OPSZ, namely propyltriethoxysilyl-substituted polymethyl(hydro)/polydimethylsilazane (namely Durazane 1500, supplied by Merck, Merck KGaA, Darmstadt, Germany) was used as precursors of the hybrid films (Figure 1).

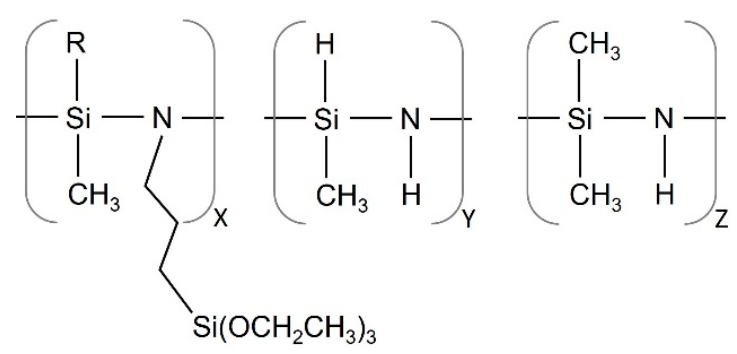

Figure 1. Schematic representation of propyltriethoxysilyl-substituted polymethyl(hydro)/polydimethylsilazane. 
The OPSZs precursor was diluted to 10, 20,30, and $40 v / v \%$ in butyl acetate. Regardless of the concentration of OPSZ in the solvent, the obtained sol was always completely transparent, and no phase separation was observed. The films were obtained by the conventional dip-coating method: A deposition time of $20 \mathrm{~s}$ and withdrawal rate of $2 \mathrm{~mm} / \mathrm{s}$ were employed. After deposition, the coated plates were conditioned in a climatic chamber at $25 \pm 2{ }^{\circ} \mathrm{C}$ and $80 \% \pm 2 \%$ R.H. during $24 \mathrm{~h}$. According to the OPSZs' chemistry, the exposure in the climatic chamber aims to promote the hydrolysis of the $\mathrm{Si}-\mathrm{O}-\mathrm{CH}_{2} \mathrm{CH}_{3}, \mathrm{Si}-\mathrm{N}, \mathrm{N}-\mathrm{H}$, and $\mathrm{Si}-\mathrm{H}$ bonds in order to form silanol groups as short-living intermediates that are responsible for the subsequent condensation and cross-linking reactions [16]. Finally, the films were cured at $100{ }^{\circ} \mathrm{C}$ for $60 \mathrm{~min}$. According to the dilution of the OPSZ precursor in the organic solvent, the labels Psz10/Psz40 were used thorough the paper.

The cured coatings were analyzed by a JEOL JSM-IT300 scanning electron microscopy (Tokyo, Japan) in order to evaluate the surface morphology and the dry thickness. For this purpose, the samples were fractured in liquid nitrogen in order to promote a brittle fracture and to observe the cross section. FT-IR analysis was recorded on a Varian 4100 FTIR Excalibur Series instrument (Palo Alto, CA, USA), exploiting the attenuated total reflectance (ATR) geometry in the wavenumber range $4000-500 \mathrm{~cm}^{-1}$ (64 scans, $4 \mathrm{~cm}^{-1}$ resolution) using a diamond crystal as the internal reflective element (IRE). The corrosion protection properties of the films were assessed by means of electrochemical techniques, such as polarization curves and electrochemical impedance spectroscopy (EIS). The electrochemical measurements were carried out using a classic three electrode configuration. The coated steel plate was the working electrode; a platinum ring counter electrode and an $\mathrm{Ag} / \mathrm{AgCl}(+210 \mathrm{mV}$ vs SHE) reference electrode were used. The investigated area was $6 \mathrm{~cm}^{2}$ and $0.1 \mathrm{M} \mathrm{NaCl}$ was used as the testing solution. The polarization curves were collected by sweeping the potential from the open circuit potential (OCP) to $+350 \mathrm{mV}$ and from the OCP to $-350 \mathrm{mV}$ for the anodic and cathodic branch of the curve, respectively. The sweep potential was set to $0.166 \mathrm{mV} / \mathrm{s}$. The polarization curves were collected after $1800 \mathrm{~s}$ of immersion in the electrolyte, in order to reach a stable value of the OCP. As far as the EIS measurements are concerned, a frequency range of $10^{5}$ to $10^{-2} \mathrm{~Hz}$ with a signal amplitude of $10 \mathrm{mV}$ (rms) were used. The evolution of the EIS spectra was assessed during $168 \mathrm{~h}$ of continuous immersion. All the electrochemical measurements were at least duplicated to assess the repeatability of the analytical methods.

\section{Results}

Figure 2 shows the appearance of the cross-section of the coatings obtained with a brittle fracture in liquid nitrogen. No pores or noticeable cracks were observed by SEM investigation, regardless of the thickness of the coatings. All the investigated coatings appeared as quite homogeneous. Notice that due to the sample preparation, the coatings are partially detached from the metal surface. The surface of the coatings seems smooth and the thickness looks quite homogenous. No cracks, defects, and pores were observed in all cases.
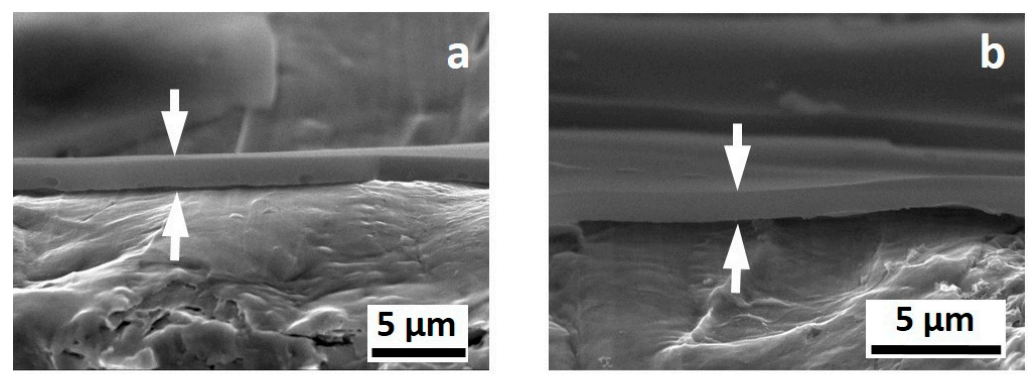

Figure 2. Cont. 

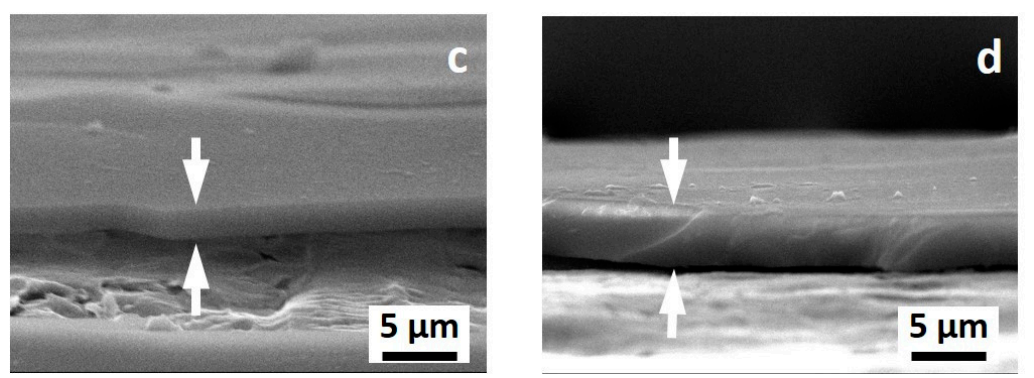

Figure 2. SEM images of the cross section of the investigated samples: PSZ-10 $v / v \%$ (a), PSZ-20 $v / v \%$ (b), PSZ-30 $v / v \%$ (c), and PSZ-40 v/v \% (d). The arrows in each figure highlight the OPSZ coating.

The effect of the processing parameters and of the dilution in butyl acetate on the dry film thickness is reported in Figure 3. All the OPSZ layers have a dry thickness higher than $1 \mu \mathrm{m}$. After increasing the concentration in OPSZ, the thickness increases, as predicted by the Landau-Levich relationship [37], due to the rise in viscosity. However, this effect is not observed when the OPSZ concentration is increased from 10 to $20 v / v \%$. It is not clear to the authors the reason behind the independency of the thickness from the OPSZ concentration below $20 v / v \%$. It seems that the viscosity of the solution below the concentration in the OPSZ of $20 v / v \%$ is not the main mechanism to control the thickness of the film. Except for the coating derived from solutions in the concentration range 10-20 v/v \%, the thickness of the deposits follows an increasing trend that is almost linear.

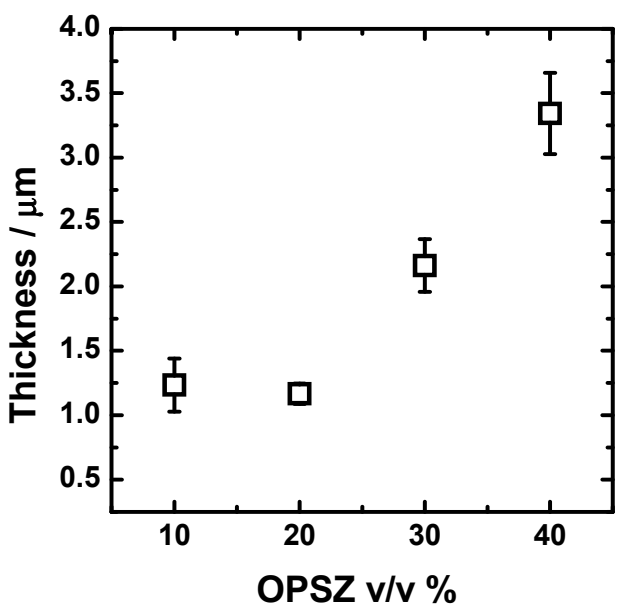

Figure 3. Effect of the dilution in butyl acetate on the dry film thickness of the OPSZ-derived coatings.

The effect of the different dilutions of PSZ in the organic solvent on the structural properties of the coatings was assessed by means of FT-IR spectroscopy. Figure 4 shows the comparison of the infra-red spectra of the PSZ coatings. The two weak peaks at 2966 and $2910 \mathrm{~cm}^{-1}$ are attributed to the $\mathrm{CH}$ asymmetric and symmetric stretching vibrations of $\mathrm{CH}_{3}$ and $\mathrm{CH}_{2}$ groups [38]. The corresponding bending vibration appears at $1268 \mathrm{~cm}^{-1}\left(\mathrm{Si}-\mathrm{CH}_{3}\right)$ [39] and at about $1408 \mathrm{~cm}^{-1}\left(\mathrm{CH}_{3}\right)$ [40]. All the spectra exhibit two intense absorption peaks in the 1200 to $1000 \mathrm{~cm}^{-1}$ range, which is attributed to the existence of a silsesquioxane network. The main signals, which are observed at 1112/1137 and 1009/1045 $\mathrm{cm}^{-1}$, are assigned to $\mathrm{Si}-\mathrm{O}$ asymmetric stretching vibrations. According to the literature [41], these signals are likely related to ladder-like polymers and closed oligosilsesquioxane cycles, respectively. The signal at 1009/1045 $\mathrm{cm}^{-1}$ shows a slight shift towards lower wavenumbers as the dilution in the organic solvent is increased $(10 v / v \% \rightarrow 40 v / v \%)$, as indicated in Table 1 . Notice that the investigated samples differ for the intensity and relative ratio of the Si-O-related peaks: The relative intensity of the peaks at 1112/1137 and 1009/1045 $\mathrm{cm}^{-1}$ (attributed to ladder-like polymers and oligosilsesquioxane cycles, respectively) exhibit little changes when increasing the PSZ concentration in the solution. The ratio between the intensity of the peak related to the oligosilsesquioxane cycles and to the ladder-like 
polymers is reported in Table 1 as the "Si-O-Si relative ratio". Notice that the ratio increases with OPSZ concertation in the dipping solution, thus suggesting that the relative amount of closed structures seems to rise with the OPSZ concentration.

Table 1. Si-O-Si asymmetric stretching band shift and relative intensity of the Si-O-Si peaks.

\begin{tabular}{ccc}
\hline Sample & Peak Position & Si-O-Si Relative Ratio \\
\hline PSZ-10 & 1045 & 0.954 \\
PSZ-20 & 1022 & 1.370 \\
PSZ-30 & 1018 & 1.577 \\
PSZ-40 & 1008 & 1.807 \\
\hline
\end{tabular}

The presence of residuals of the $\mathrm{Si}-\mathrm{N}-\mathrm{Si}$ network is confirmed by the presence of the weak shoulder at $1177 \mathrm{~cm}^{-1}$ (NH deformation in $\mathrm{Si}-\mathrm{N}-\mathrm{Si}$ ) [42] and by the peak at $910 \mathrm{~cm}^{-1}$ (Si-N stretching in $\mathrm{Si}-\mathrm{N}-\mathrm{Si}$ ) [43]. The strong absorption band at $774 \mathrm{~cm}^{-1}$ is attributed to the $\mathrm{Si}-\mathrm{C}$ bond [40] of the hydrocarbon substituents bonded to the Si atoms. The presence of the absorption band related to the $\mathrm{Si}-\mathrm{H}$ bond was not observed. The FT-IR investigation indicates the presence of peaks, which can be attributed both to the $\mathrm{Si}-\mathrm{O}-\mathrm{Si}$ as well as to the $\mathrm{Si}-\mathrm{N}-\mathrm{Si}$ network. These findings suggest that: (1) The curing condition employed in this study does not promote a complete curing (hydrolysis of all the $\mathrm{NH}$ is not achieved) of the film; (2) the hydrolysis of the $\mathrm{Si}-\mathrm{H}$ bonds seems to be almost completed; and (3) a sort of two-phase material, consisting of non-converted polysilazane domains ( $\mathrm{Si}-\mathrm{N}-\mathrm{Si}$ ) and polysilsesquioxane ( $\mathrm{Si}-\mathrm{O}-\mathrm{Si})$ domains seems to have formed.

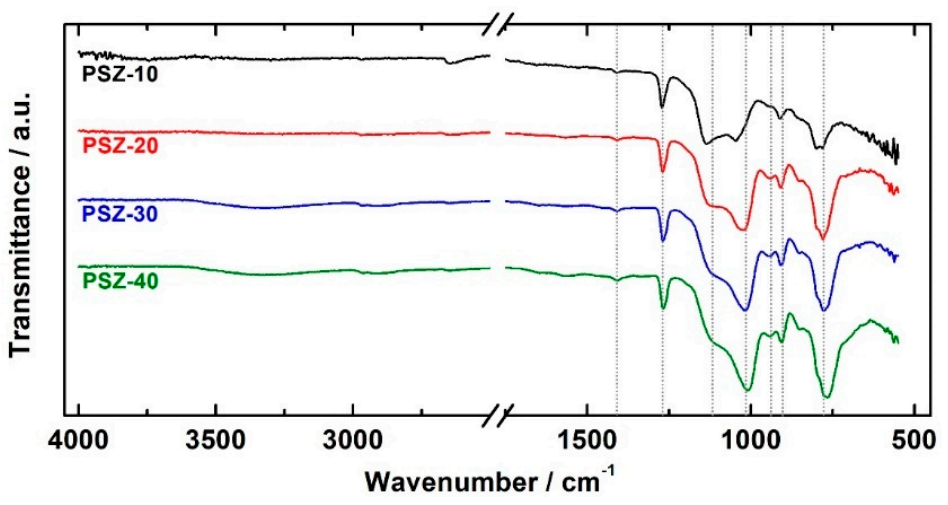

Figure 4. FT-IR spectra of the investigated coatings.

The anodic and cathodic polarization curves collected upon immersion of the samples in $0.1 \mathrm{M}$ $\mathrm{NaCl}$ are reported in Figure $5 \mathrm{a}, \mathrm{b}$, respectively. Notice that the presence of the coating promotes a shift toward higher values of the open circuit potential (OCP), which increases from about $-0.60 \mathrm{~V}$ to about $-0.42 /-0.46 \mathrm{~V}$. The different thicknesses seem not to remarkably affect the OCP value. The increase in OCP is likely to be related to the presence of the film, which reduces the anodic activity of the substrate. Regardless of the OPSZ dilution, anodic and cathodic current densities are shifted toward lower values compared to the bare substrate. More precisely, the increase in film thickness promotes a decrease in both anodic and cathodic current density. The effect appears to be more marked in the anodic part of the curve as the current density is reduced of about three orders of magnitude. This current density decrease is likely to be related to the ohmic drop due to the presence of a dielectric coating. The electrochemical activity detected is probably related to the local electrochemical activity, which can be measured where the coatings are not completely protective (i.e., in correspondence with the defects, such as micro-pores or cracks). 

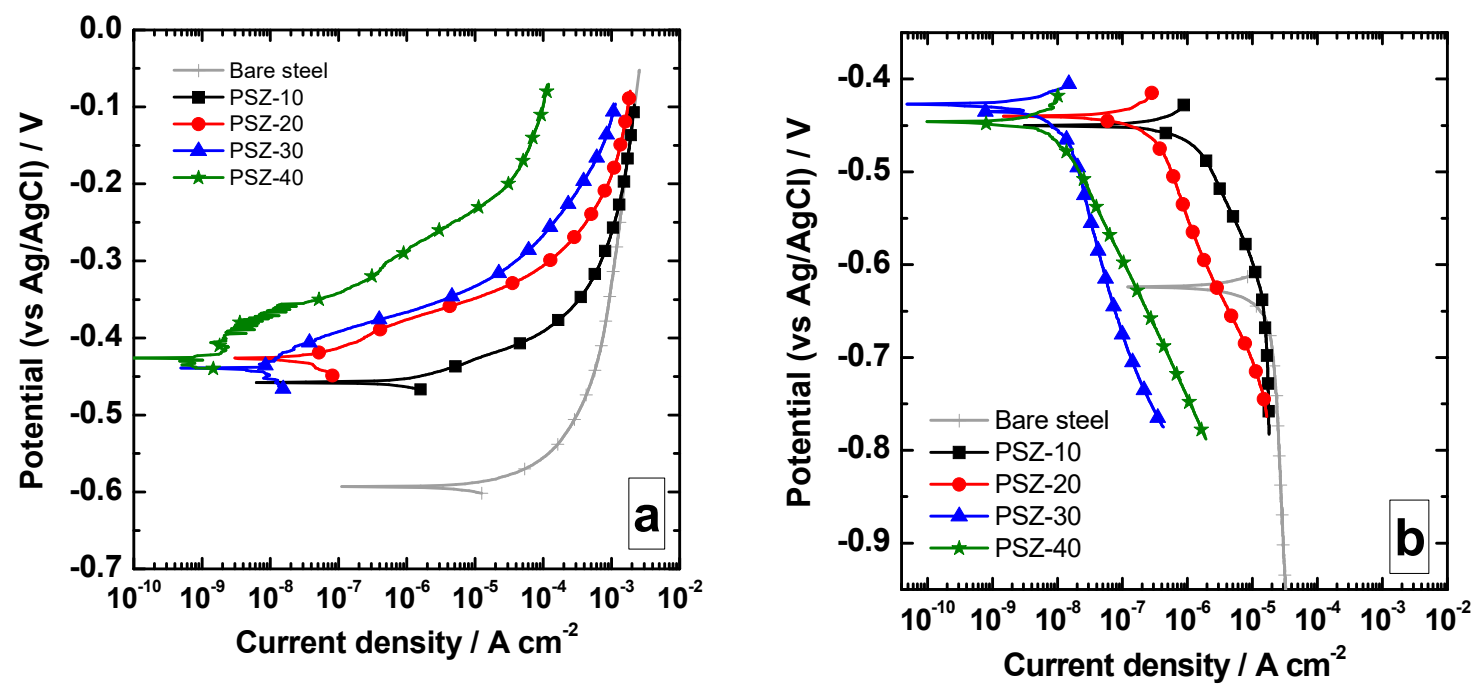

Figure 5. Anodic (a) and cathodic (b) polarization curves collected over the investigated samples in $0.1 \mathrm{M} \mathrm{NaCl}$.

The evolution of the open circuit potential versus immersion time during one week of continuous immersion in the $0.1 \mathrm{M} \mathrm{NaCl}$ solution is reported in Figure 6. Compared to the bare substrate, all the coated steel panels except PSZ-10 show a higher potential value, at least in the very first hours of immersion. The PSZ-20, PSZ-30, and PSZ-40 samples maintain remarkably higher values of the open circuit potential at least for $24 \mathrm{~h}$ of continuous immersion. As time elapsed, a gradual decrease in OCP was observed for all the investigated samples. In particular, the samples derived from $10 v / v \%$ OPSZ show a steep drop in the OCP after the very first hours of immersion in the electrolyte, behaving almost like the bare sample.

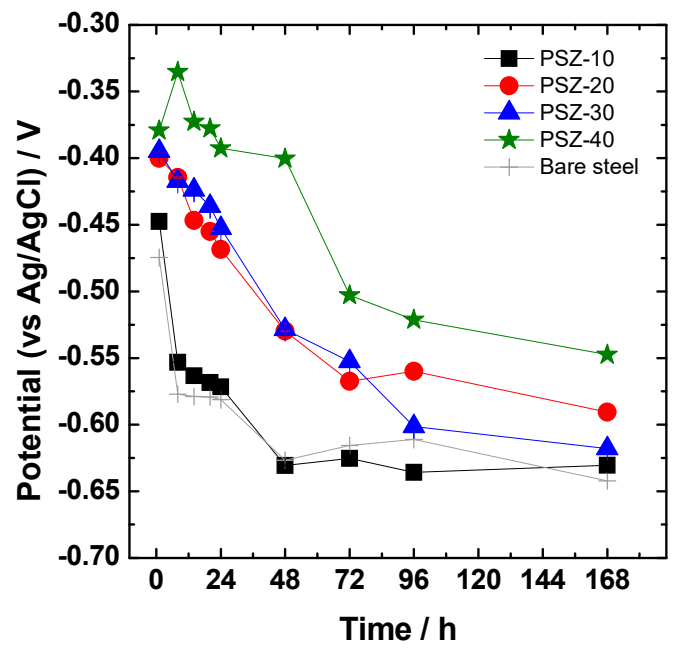

Figure 6. Evolution with immersion time in $0.1 \mathrm{M} \mathrm{NaCl}$ of the open circuit potential (OCP).

EIS measurements were performed to evaluate the electrochemical properties of the investigated coatings during immersion time in $0.1 \mathrm{M} \mathrm{NaCl}$ solution. Figure $7 \mathrm{a}-\mathrm{h}$ show the time evolution of the impedance modulus and phase for the coating object of the present study during $168 \mathrm{~h}$ of continuous immersion. The spectra of the bare low-carbon steel are reported for comparison. Notice that the Lissajous plots related to the experimental point located in the low frequency range highlight a non-linear response. This is evident also from Figure 7a, where the experimental points in the low frequency range looks scattered for all the investigated samples. For this reason, the results of the fitting of the experimental spectra in the low frequency range are not strictly reliable. The spectra are 
therefore discussed also in qualitative terms by considering the modulus of the impedance in the low frequency range as a rough estimation of the overall protection properties of the coatings.

As far as the EIS response after $1 \mathrm{~h}$ of immersion is concerned (Figure 7a,b), remarkable differences were observed among the coatings under investigation. PSZ-40 shows the highest impedance modulus in the low frequency range $\left(|\mathrm{Z}|_{0.01} \mathrm{~Hz} \approx 6 \times 10^{5} \Omega \mathrm{cm}^{2}\right)$, thus suggesting the best protection efficiency among the studied coatings (Figure 7a). The bare sample shows a $|\mathrm{Z}|_{0.01} \mathrm{~Hz} \approx 5 \times 10^{2} \Omega \mathrm{cm}^{2}$ while the samples PSZ-10, PSZ-20, and PSZ-30 of about $3 \times 10^{3}, 3 \times 10^{4}$, and $2 \times 10^{5} \Omega \mathrm{cm}^{2}$, respectively. As far as the impedance modulus after $1 \mathrm{~h}$ of immersion is concerned, all the coatings are at least slightly protective to the substrate. Considering the phase angle plot for the sample PSZ-40 (Figure 7b), three relaxation processes can be observed: A high frequency time constant at about $10^{4} \mathrm{~Hz}$, a middle frequency time constant at about $10^{1} \mathrm{~Hz}$, and a low frequency time constant at $10^{-1} \mathrm{~Hz}$. According to the literature $[8,44]$, the high frequency relaxation process has been attributed to the hybrid coating. The low frequency time constant is expected to be related to the faradic process occurring at the metal substrate, while the physical meaning of the relaxation process occurring in the middle frequency range is not clear. According to the literature [40], it is likely to be related to the metal/hybrid network interface and/or to the corrosion products accumulating at the metal/solution interface. On the other hand, the samples derived from 20 and $30 v / v \%$ OPSZ solutions show two relaxation processes located at about $10^{3} / 10^{4}$ and $10^{0} \mathrm{~Hz}$, which are attributed to the contribution of the coating and the faradic process, respectively. The sample PSZ-10 shows an impedance spectrum very close to the bare substrate, thus proving a very low extent of corrosion protection. In fact, the relaxation process corresponding to the presence of the coating (located in the $10^{3} / 10^{4} \mathrm{~Hz}$ frequency range) is not observed in the phase angle plot in Figure $7 \mathrm{~b}$.
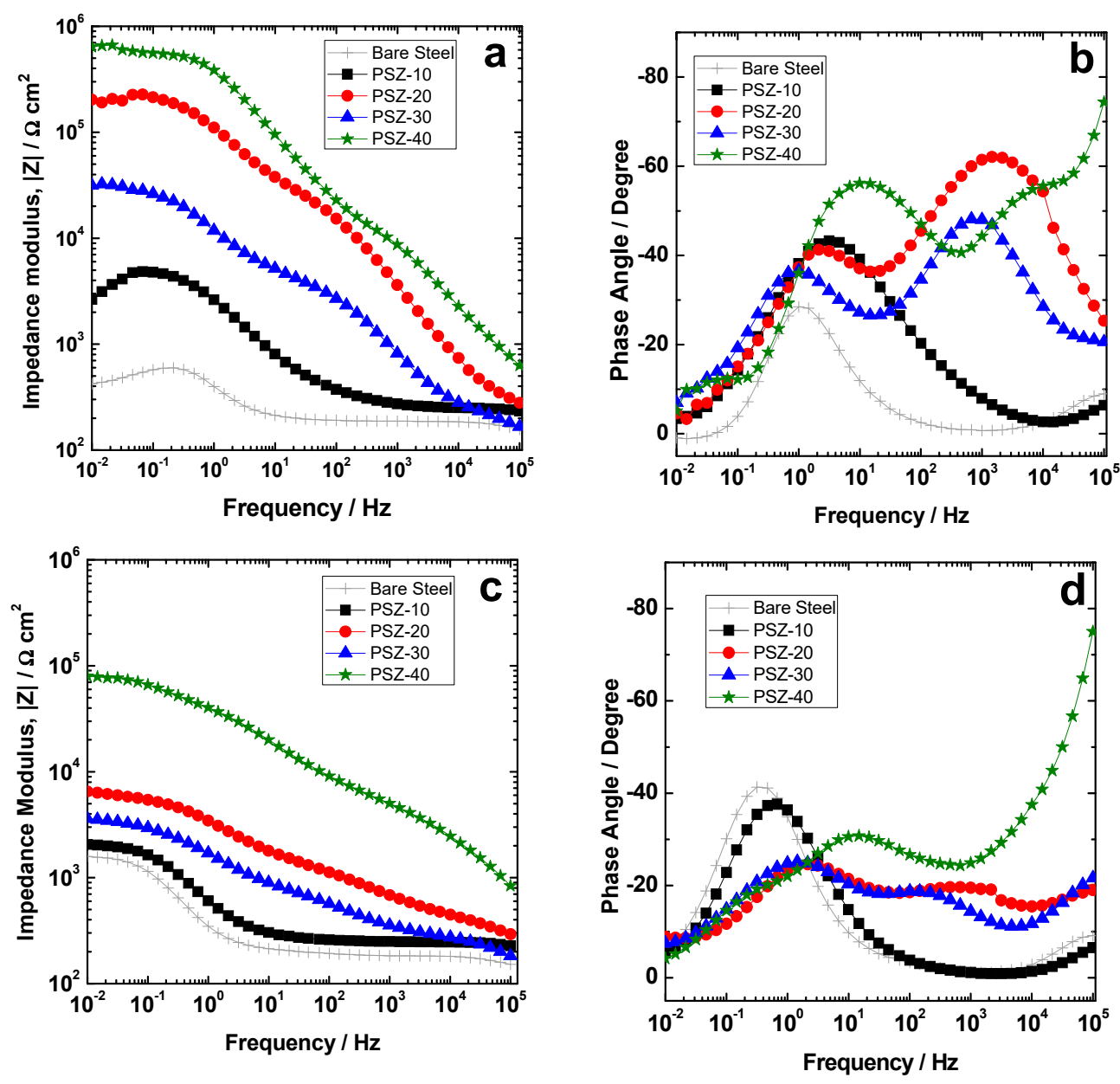

Figure 7. Cont. 

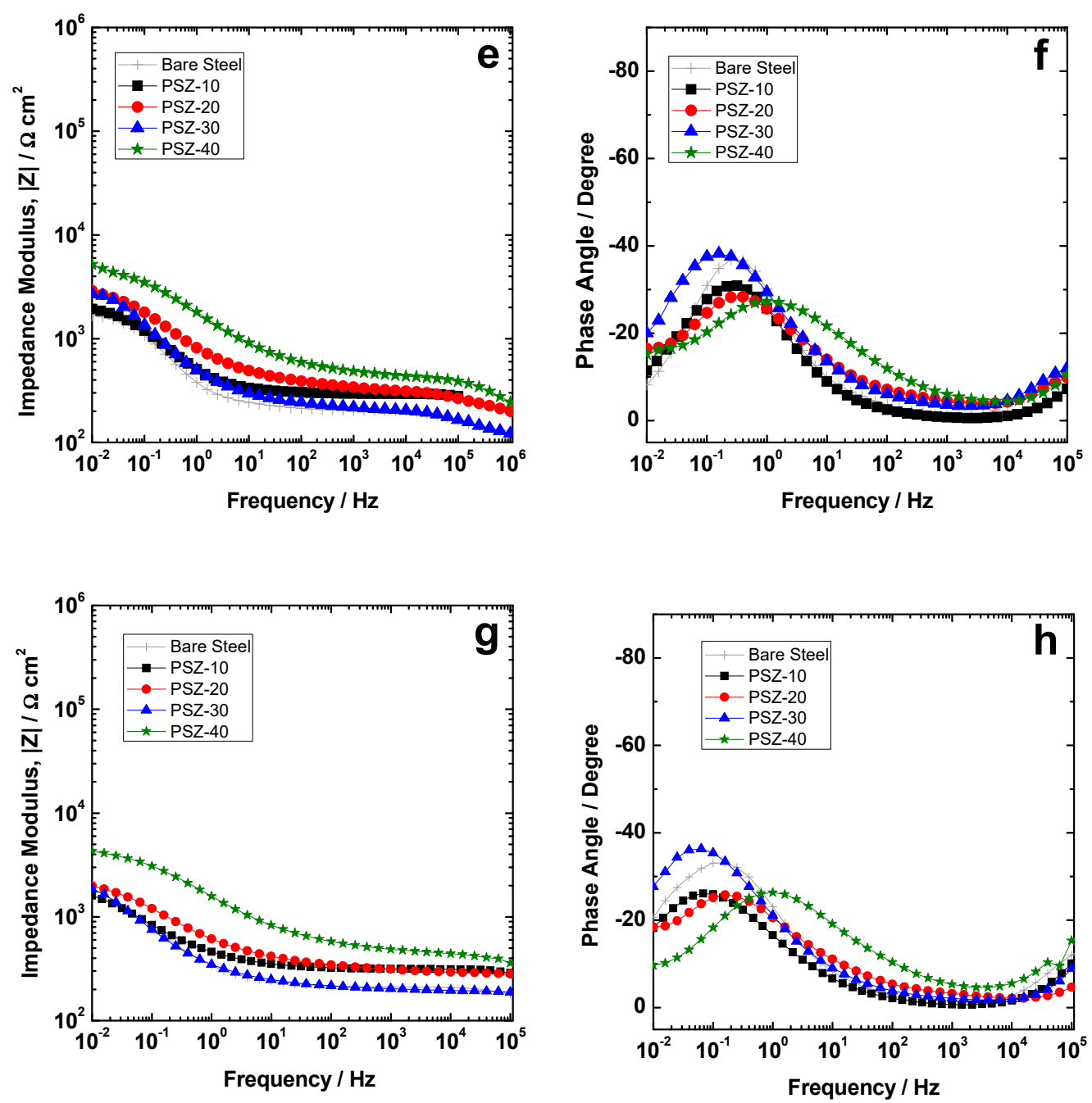

Figure 7. Modulus and phase spectra of the investigated coatings compared to the bare substrate during immersion time: (a,b) $1 \mathrm{~h},(\mathbf{c}, \mathbf{d}) 24 \mathrm{~h},(\mathbf{e}, \mathbf{f}) 72 \mathrm{~h}$, and (g,h) $168 \mathrm{~h}$.

The evolution with immersion time further confirms the initial observations. According to the polarization curves, the coating derived from $10 v / v \%$ OPSZ solution does not provide the substrate with any significant improvement in terms of corrosion resistance and it behaves approximately like the bare substrate. Probably, the hybrid coating, which is present on the steel substrate, is defective and/or porous, thus allowing the electrolyte to easily reach the metal interface and promoting the corrosion of the substrate. The differences among the investigated samples are still noticeable after $24 \mathrm{~h}$ of continuous immersion (Figure 7c,d). The sample PSZ-40 still shows the highest impedance among the studied samples. The samples derived from 20 and $30 v / v \%$ OPSZ in the solution show comparable values of the impedance modulus, slightly higher for the PSZ-20 sample. Notice that, even if samples PSZ-10 and PSZ-20 have almost the same thickness (slightly higher than $1 \mu \mathrm{m}$ ), according to the EIS spectra in Figure 7, the latter seems to be remarkably more protective. The reason for this finding is not completely clear to the authors. The authors did not observe any macro-pore or defect in the PSZ-10\% coating. However, although not unequivocally proven by the experimental observation, a possible explanation for the reduced extent of protection of the samples derived from $10 v / v \%$ OPSZ relies on the presence of micro-defects, micro-pores, and any heterogeneity, which can be more relevant for the sample derived from $10 v / v \%$ OPSZ with respect to the sample derived from $20 v / v \%$ OPSZ.

On the other hand, even if the coating derived from a $30 v / v \%$ PSZ solution has approximately double the thickness of PSZ-20, the anodic current density during polarization (Figure 5a) and the impedance spectra (Figure 7) are very similar. With immersion time, the differences among the samples 
become less and less significant. Figure $7 \mathrm{e}, \mathrm{f}$ shows the impedance modulus and phase, respectively, after $72 \mathrm{~h}$ of continuous immersion: The impedance curve for the bare steel is almost stable $\left(|\mathrm{Z}|_{0.01} \mathrm{~Hz} \approx\right.$ $2 \times 10^{2} \Omega \mathrm{cm}^{2}$ ) while the coated samples shows a decrease of the low frequency impedance to about $2 / 5 \times 10^{2} \Omega \mathrm{cm}^{2}$ ). The differences among the investigated coatings are very slight and the improvement in terms of corrosion resistance compared to the bare substrate is strongly reduced compared to the initial stage of immersion. After $168 \mathrm{~h}$ of exposure to the electrolyte (Figure $7 \mathrm{~g}, \mathrm{~h}$ ), the differences among the studied coatings are further reduced.

The EIS spectra showed in Figure 7a,b were further investigated by means of electrical equivalent circuits (e.e.c.s) in order to obtain a deeper knowledge of the properties of the OPSZ coatings in the very first hours of immersion. According to the previous description of the observed relaxation processes, the experimental spectra of samples derived from 20,30, and $40 v / v \%$ OPSZ were fitted employing a $\mathrm{R}_{\mathrm{e}}\left(\mathrm{CPE}_{\text {coat }}\left(\mathrm{R}_{\text {coat }}\left(\mathrm{CPE}_{\mathrm{MF}} \mathrm{R}_{\mathrm{MF}}\right)\right)\right)$ electrical equivalent circuit (see Figure $\left.8 \mathrm{a}\right)$. In the above-mentioned circuit, $R_{\mathrm{e}}$ stands for the resistance of the electrolyte. The time constant in the middle/high frequency range is attributed to the OPSZ layer. A resistive element, $R_{\text {coat }}$, which indicates the pore resistance of the OPSZ layer, and a constant phase element, $\mathrm{CPE}_{\text {coat, }}$ which represents its dielectric properties, were employed. The relaxation process in the middle frequencies (MF) is related to different processes depending on the different samples: (i) For the sample PSZ-40, it is likely to be attributed to the metal/hybrid network interface [40]; and (ii) for the samples PSZ-30 and PSZ-20, it is likely to be attributed to the faradic process occurring at the metal interface. According to this explanation, a resistance, $\mathrm{R}_{\mathrm{MF}}$, and a constant phase element, $\mathrm{CPE}_{\mathrm{MF}}$, were employed.
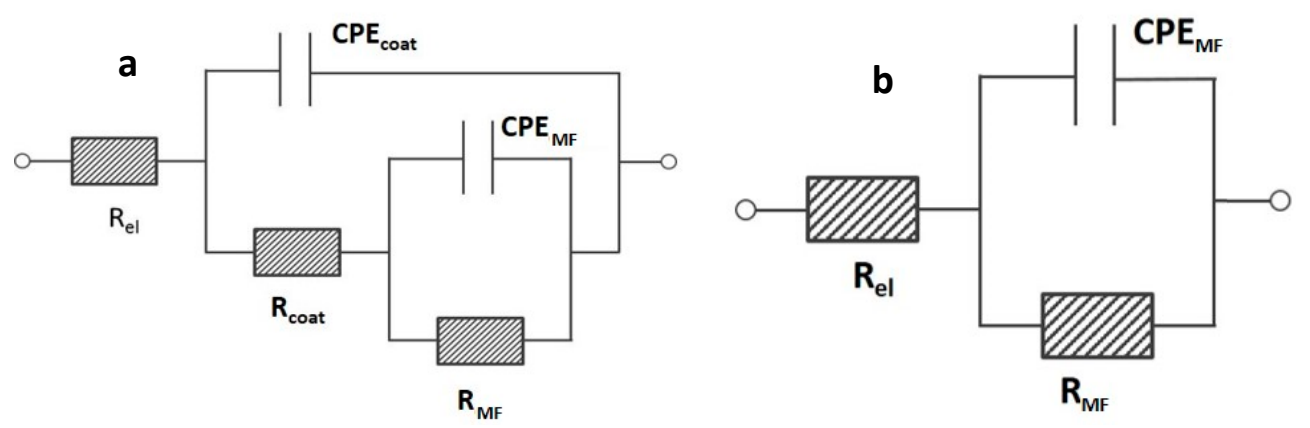

Figure 8. Electrical equivalent circuits employed to fit the experimental spectra (a) of samples PSZ-20, PSZ-30, PSZ-40 and (b) of samples PSZ-10 and the bare steel.

As far as the bare substrate and the sample PSZ-10 are concerned, the experimental spectra were fitted employing a $R_{e}\left(C P E_{M F} R_{M F}\right)$ electrical equivalent circuit (see Figure $8 b$ ). In the above-mentioned circuit, $R_{\mathrm{e}}$ stands for the resistance of the electrolyte, $R_{\mathrm{MF}}$ for the resistance attributed to the faradic process, and $\mathrm{CPE}_{\mathrm{MF}}$ for the constant phase element attributed to the dielectric properties of the metal/solution interface.

Considering the mathematical representation of a CPE (i.e., $Z_{\mathrm{CPE}}=1 /\left(Q(\omega \mathrm{j})^{\alpha}\right)$, the parameters $Q$ and $\alpha$ were employed to describe the dielectric response of the electrodes. Table 2 shows the output of the fitting.

Table 2. Fitting parameters: $R_{\text {coat }}, Q_{\text {coat }}, \alpha_{\text {coat }}, R_{\mathrm{MF}}, Q_{\mathrm{MF}}$, and $\alpha_{\mathrm{MF}}$ of spectra at $1 \mathrm{~h}$ of immersion.

\begin{tabular}{|c|c|c|c|c|c|c|}
\hline Sample & $\begin{array}{l}R_{\text {coat }} \\
\Omega \mathrm{cm}^{2}\end{array}$ & $\begin{array}{c}Q_{\text {coat }} \\
\Omega^{-1} \mathrm{~cm}^{-2} \mathrm{~s}^{\alpha}\end{array}$ & $\alpha_{\text {coat }}$ & $\begin{array}{c}R_{\mathrm{MF}} \\
\Omega \mathrm{cm}^{2}\end{array}$ & $\stackrel{Q_{M F}}{\Omega^{-1} \mathrm{~cm}^{-2} \mathrm{~s}^{\alpha}}$ & $\alpha_{\mathrm{MF}}$ \\
\hline Bare & - & - & - & $4.6 \times 10^{2}$ & $5.6 \times 10^{-4}$ & 0.87 \\
\hline PSZ-10 & - & - & - & $2.1 \times 10^{3}$ & $1.8 \times 10^{-4}$ & 0.82 \\
\hline PSZ-20 & $3.4 \times 10^{4}$ & $3.4 \times 10^{-7}$ & 0.76 & $1.9 \times 10^{5}$ & $1.7 \times 10^{-6}$ & 0.77 \\
\hline PSZ-30 & $5.4 \times 10^{3}$ & $3.4 \times 10^{-6}$ & 0.67 & $2.9 \times 10^{4}$ & $2.2 \times 10^{-5}$ & 0.74 \\
\hline PSZ-40 & $2.4 \times 10^{4}$ & $2.5 \times 10^{-7}$ & 0.67 & $6.3 \times 10^{5}$ & $2.0 \times 10^{-7}$ & 0.82 \\
\hline
\end{tabular}


As far as Table 2 is concerned, notice that it is not possible to attribute to the pre-exponential factors, $Q_{\text {coat }}$ and $Q_{\mathrm{MF}}$, any precise physical meaning since the parameters $\alpha_{\text {coat }}$ and $\alpha_{\mathrm{MF}}$ are quite far from unity (range from 0.67 to 0.87 ). The fitting parameters reported in Table 2 suggest that the coatings derived from more concentrated OPSZ solutions are more protective, even if the barrier properties seem to be influenced by the presence of defects. In fact, the observed increase in coating thickness with OPSZ concertation in the solution does not directly correspond to an enhancement in the pore resistance of the coating $\left(R_{\text {coat }}\right)$.

The appearance of the samples (Figure 9) supports the EIS findings: No remarkable differences were observed among the exposed surfaces after $168 \mathrm{~h}$ of continuous immersion. The amount of corrosion products looks very similar regardless of the thickness of the PSZ coating, thus proving that the protection of the steel substrate is not lasting for more than a few days in a chloride-containing medium. Notice that the bare substrate shows a homogeneous corrosion attack over all the surface while for the coated samples it is not the same. When the coating is present, the attack seems to be more localized: Again, it is likely that micro-defects or micro-pores act as weak points through which the electrolyte can pass, thus reaching the metal surface.
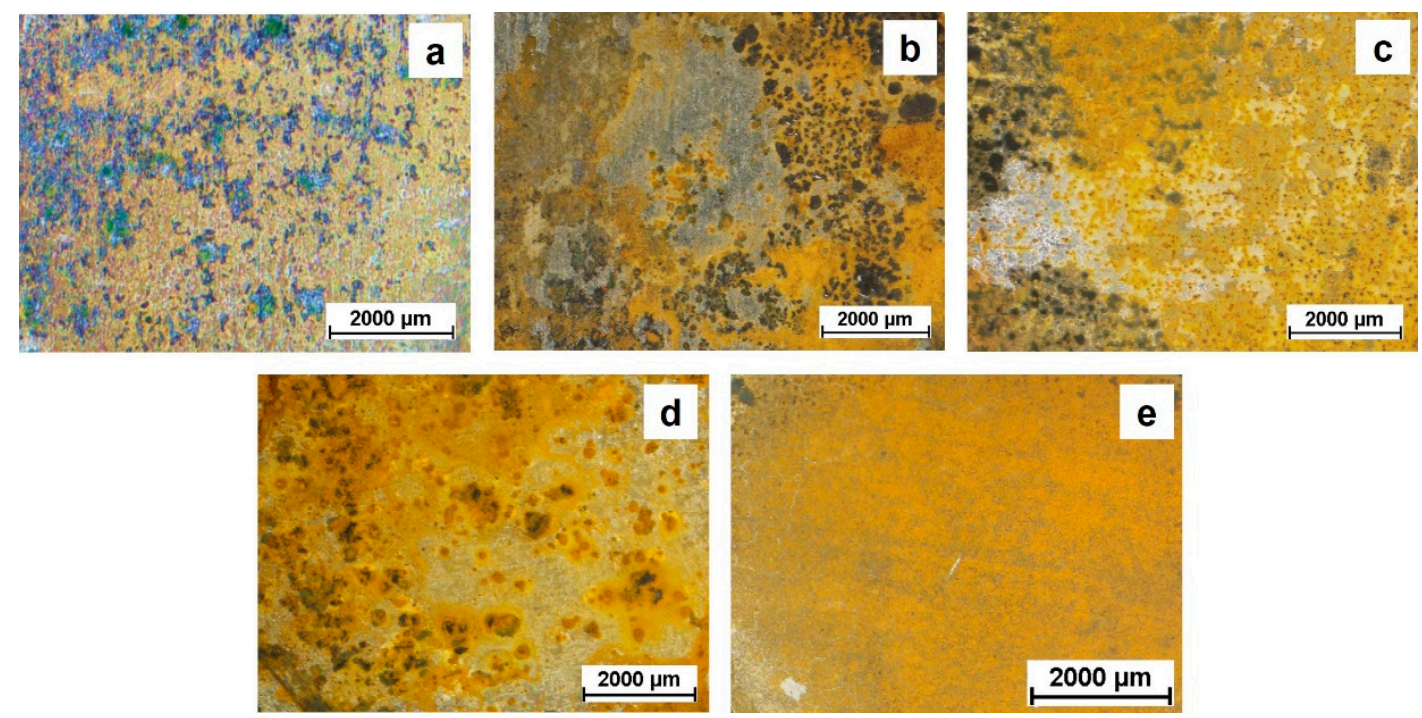

Figure 9. Visual appearance of the investigated samples after one week (168 h) of immersion in the 0.1 M NaCl solution: (a) PSZ-10, (b) PSZ-20, (c) PSZ-30, (d) PSZ-40, and (e) bare steel.

\section{Discussion}

The extent of corrosion protection of the hybrid coatings investigated in the present study was compared with literature data related to sol-gel based protective coatings for mild steel in chloride-containing environments. Table 3 shows a comparison between the low frequency impedance $|\mathrm{Z}|_{0.01} \mathrm{~Hz}$ in the first hours of immersion in chloride media for sol-gel-derived coatings based mainly on polysiloxanes. The low frequency impedance was selected for the comparison as it is a rough but reliable estimation of the overall protection properties of the coatings. The literature data were compared with the result of the present study related to the PSZ-40 sample. 
Table 3. Literature data comparison of the impedance modulus at $0.01 \mathrm{~Hz}\left(|\mathrm{Z}|_{0.01}\right)$. Only neat hybrid sol-gel coatings were considered, without the addition of any inhibitor, pigment, or dye. "NP" stands for "not provided". [*] Abbreviations report the acronyms.

\begin{tabular}{|c|c|c|c|c|}
\hline Precursors* & Electrolyte and Time & $|\mathrm{Z}|_{0.01}\left(\Omega \mathrm{cm}^{2}\right)$ & Thickness $(\mu \mathrm{m})$ & Ref. \\
\hline TEOS-MTES & 3.5 wt. $\% \mathrm{NaCl}(1 \mathrm{~h})$ & $9 \times 10^{4}$ & $3-4$ & [45] \\
\hline TEOS-MTES-GPTMS & $0.1 \mathrm{M} \mathrm{NaCl}(8 \mathrm{~h})$ & $10^{4}$ & NP & [46] \\
\hline TEOS-MTES & 3.5 wt. $\% \mathrm{NaCl}(2 \mathrm{~h})$ & $3 \times 10^{5}$ & 1.14 & [47] \\
\hline TEOS-GPTMS & 3.5 wt. $\% \mathrm{NaCl}(48 \mathrm{~h})$ & $3 \times 10^{6}$ & $20-40$ & [10] \\
\hline APTES & 3.5 wt. $\% \mathrm{NaCl}(2 \mathrm{~h})$ & $7 \times 10^{2}$ & $1.8 / 2.0$ & [48] \\
\hline TEOS-GPTMS-DMODS & 3.5 wt. $\% \mathrm{NaCl}$ (20 days) & $6 \times 10^{4}$ & 13 & [49] \\
\hline TEOS-GPTMS-MTES & $0.1 \mathrm{M} \mathrm{NaCl}(6 \mathrm{~h})$ & $10^{4}$ & $\approx 0.5$ & [50] \\
\hline TEOS-MTMS & 3.5 wt. $\% \mathrm{NaCl}(1 \mathrm{~h})$ & $1.26 \times 10^{5}$ & 7.6 & [51] \\
\hline MTES-TEOS & 3.5 wt. $\% \mathrm{NaCl}(2 \mathrm{~h})$ & $3.2 \times 10^{4}$ & NP & [52] \\
\hline APTES-Epoxy & 3.5 wt. $\% \mathrm{NaCl}(3 \mathrm{~h})$ & $2 \times 10^{3}$ & $2 / 10$ & [53] \\
\hline TEOS-GPTMS-MTES & $0.1 \mathrm{M} \mathrm{NaCl}(2 \mathrm{~h})$ & $3 \times 10^{4}$ & $\approx 0.34$ & [11] \\
\hline TEOS-GPTMS-MTES & $0.1 \mathrm{M} \mathrm{NaCl}(8 \mathrm{~h})$ & $10^{4}$ & $\approx 0.26$ & [9] \\
\hline PSZ-40 & $0.1 \mathrm{M} \mathrm{NaCl}(1 \mathrm{~h})$ & $6 \times 10^{5}$ & & \\
\hline PSZ-40 & $0.1 \mathrm{M} \mathrm{NaCl}(24 \mathrm{~h})$ & $8 \times 10^{4}$ & 3.4 & This work \\
\hline
\end{tabular}

The thickness of the coating objects of the comparative evaluation are reported for the sake of clarity. Notice that the $|Z|_{0.01} \mathrm{~Hz}$ of the PSZ-40 coating is at least competitive with the most protective silicon alkoxide-derived coatings, at least as far as the initial electrochemical properties are concerned. Based on the comparison reported in Table 2, OPSZ-derived coatings seem to be considered as a potential alternative to silicon alkoxides for the protection of mild steel in chloride-containing media. On the other hand, the long-term corrosion protection properties of the investigated coatings seem to be not noteworthy. However, notice that most of the literature data related to the EIS response with immersion time are provided only for relatively short immersion time: This is often after a few hours (2 h [48], $3 \mathrm{~h} \mathrm{[53],} 6 \mathrm{~h} \mathrm{[50],} 8 \mathrm{~h}$ [46], $24 \mathrm{~h}$ [52]), occasionally after a few days (48 h [10,51] and

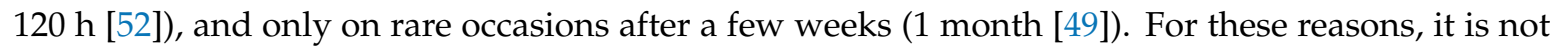
possible to properly compare the long-term stability of the investigated coatings with other findings in the literature. In any case, one should consider that the OPSZ-derived coatings are designed to be employed as a pre-treatment prior to painting or for exposure in mild environments. Accordingly, the long-term stability upon direct exposure to an aggressive electrolyte is not of major importance for such kinds of applications.

\section{Conclusions}

The effect of the dilution in butyl-acetate on the final properties of hybrid coatings derived from polyorganosilazane precursors based on polymethyl-(hydro)/polydimethylsilazane was investigated for the corrosion protection of mild steel in a chloride medium. FT-IR spectroscopy seems to suggest that the hybrid coating structure consists of a combination of non-converted polysilazane domains ( $\mathrm{Si}-\mathrm{N}-\mathrm{Si}$ ) and polysilsesquioxane (Si-O-Si) domains. The corrosion protection properties, assessed by means of polarization curves and EIS, remarkably increase for thicker coatings, in particular for OPSZ precursor concentrations of about $40 v / v \%\left(|Z|_{0.01} \mathrm{~Hz} \approx 6 \times 10^{5} \Omega \mathrm{cm}^{2}\right.$ after $1 \mathrm{~h}$ of immersion in $0.1 \mathrm{M}$ $\mathrm{NaCl}$ ). All the OPSZ-derived coatings were proven to be protective to the mild steel substrate, even if a clear relationship with the thickness of the coatings was not observed. A possible explanation, even if not unequivocally proven by the experimental results, relies on the presence of defects, which affects the electrochemical response of the coatings. Compared to literature data related to silicon alkoxide-based coatings applied by means of the sol-gel method on mild steel, the PSZ-40 coating was proven to show competitive corrosion protection properties (evaluated in terms of $|\mathrm{Z}|_{0.01} \mathrm{~Hz}$ ), at least as far as the initial immersion hours are considered. On the other hand, further investigation is needed in order to improve the durability of the coatings upon direct exposure to an aggressive 
environment. A possible strategy to overcome the long-term durability issue is to work with more concentrated solutions and/or to change the conditioning atmosphere $(\mathrm{T}, \mathrm{t}$, and r.h.) in order to obtain more protective coatings.

Author Contributions: Conceptualization, S.R. and M.F.; methodology, M.F., S.R. and F.J.R.G.; software, F.J.R.G.; validation, M.F., S.R. and F.D.; formal analysis, F.J.R.G. and M.F.; investigation, F.J.R.G. and M.F.; resources, F.D. and S.R.; data curation, F.J.R.G. and M.F.; writing —original draft preparation, M.F. and S.R.; writing-review and editing, F.D. and F.J.R.G.; visualization, M.F.; supervision, F.D. and S.R.; project administration, M.F. and S.R.; funding acquisition, F.D. and S.R.

Funding: This research received no external funding.

Acknowledgments: The authors are grateful to Stefano Corrado (Merck SpA, Milan, Italy) for supplying the OPSZ precursors and to Pietro Zandonai for the experimental work.

Conflicts of Interest: The authors declare no conflict of interest.

\section{Abbreviations}

$\begin{array}{ll}\text { TEOS } & \text { Tetraethyl-orthosilicate } \\ \text { MTES } & \text { Methyltriethoxysilane } \\ \text { GPTMS } & \text { Glycidyloxypropyltrimethoxysilane } \\ \text { APTES } & \text { (3-Aminopropyl)triethoxysilane } \\ \text { DMODS } & \text { Dimethyl octadecylsilane } \\ \text { MTMS } & \text { Trimethoxymethylsilane } \\ \text { PMDMS } & \text { polymethyl(hydro)/polydimethylsilazane }\end{array}$

\section{References}

1. Fenker, M.; Balzer, M.; Kappl, H. Corrosion protection with hard coatings on steel: Past approaches and current research efforts. Surf. Coat. Technol. 2014, 257, 182-205. [CrossRef]

2. Liu, C.; Bi, Q.; Matthews, A. EIS comparison on corrosion performance of PVD TiN and CrN coated mild steel in $0.5 \mathrm{~N} \mathrm{NaCl}$ aqueous solution. Corros. Sci. 2001, 43, 1953-1961. [CrossRef]

3. Hausbrand, R.; Bolado-Escudero, B.; Dhont, A.; Wielant, J. Corrosion of flame-assisted CVD silica-coated steel sheet. Corros. Sci. 2012, 61, 28-34. [CrossRef]

4. Zhang, J.; Xue, Q.; Li, S. Microstructure and corrosion behavior of TiC/Ti(CN)/TiN multilayer CVD coatings on high strength steels. Appl. Surf. Sci. 2013, 280, 626-631. [CrossRef]

5. Díaz, B.; Härkönen, E.; Swiatowska, J.; Maurice, V.; Seyeux, A.; Marcus, P.; Ritala, M. Low-temperature atomic layer deposition of $\mathrm{Al}_{2} \mathrm{O}_{3}$ thin coatings for corrosion protection of steel: Surface and electrochemical analysis. Corros. Sci. 2011, 53, 2168. [CrossRef]

6. Potts, S.E.; Schmalz, L.; Fenker, M.; Díaz, B.; Swiatowska, J.; Maurice, V.; Seyeux, A.; Marcus, P.; Radnóczi, G.; Toth, L.; et al. Ultra-thin aluminium oxide films deposited by plasma-enhanced atomic layer deposition for corrosion protection. J. Electrochem. Soc. 2011, 158, C132-C138. [CrossRef]

7. Delimi, A.; Galopin, E.; Coffinier, Y.; Pisarek, M.; Boukherrou, R.; Talhi, B.; Szunerits, S. Investigation of the corrosion behavior of carbon steel coated with fluoropolymer thin films. Surf. Coat. Technol. 2011, 205, 4011-4017. [CrossRef]

8. Lavollée, C.; Gressier, M.; Garcia, J.; Sobrino, J.-M.; Reby, J.; Menu, M.-J.; Rossi, S.; Fedel, M. New architectured hybrid sol-gel coatings for wear and corrosion protection of low-carbon steel. Prog. Org. Coat. 2016, 99, 337-345.

9. Asadi, N.; Naderi, R.; Saremi, M.; Arman, S.Y.; Fedel, M.; Deflorian, F. Study of corrosion protection of mild steel by eco-friendly silane sol-gel coating. J. Sol Gel Sci. Technol. 2014, 70, 329-338. [CrossRef]

10. Mora, L.V.; Naik, S.; Paul, S.; Dawson, R.; Neville, A.; Barker, R. Influence of silica nanoparticles on corrosion resistance of sol-gel based coatings on mild steel. Surf. Coat. Technol. 2017, 324, 368-375. [CrossRef]

11. Taheri, M.; Naderi, R.; Saremi, M.; Mahdavian, M. Development of an ecofriendly silane sol-gel coating with zinc acetylacetonate corrosion inhibitor for active protection of mild steel in sodium chloride solution. J. Sol. Gel. Sci. Technol. 2017, 81, 154-166. [CrossRef] 
12. Santana, I.; Pepe, A.; Schreiner, W.; Pellice, S.; Ceré, S. Hybrid sol-gel coatings containing clay nanoparticles for corrosion protection of mild steel. Electrochim. Acta 2016, 203, 396-403. [CrossRef]

13. Sugama, T.; Carciello, N. Pre-ceramic polysilazane coatings for cold-rolled steels. Mater. Lett. 1992, 14, 322-328. [CrossRef]

14. Schütz, A.; Günthner, M.; Motz, G.; Greißl, O.; Glatzel, U. Characterisation of novel precursor-derived ceramic coatings with glass filler particles on steel substrates. Surf. Coat. Technol. 2012, 207, 319-327. [CrossRef]

15. Günthner, M.; Kraus, T.; Krenkel, W.; Motz, G.; Dierdorf, A.; Decker, D. Particle-filled PHPS silazane-based coatings on steel. Int. J. Appl. Ceram. Technol. 2009, 6, 373-380. [CrossRef]

16. Bauer, F.; Decker, U.; Dierdorf, A.; Ernst, H.; Heller, R.; Liebe, H.; Mehnert, R. Preparation of moisture curable polysilazane coatings: Part I. Elucidation of low temperature curing kinetics by FT-IR spectroscopy. Prog. Org. Coat. 2005, 53, 183-190. [CrossRef]

17. D'Elia, R.; Dusserre, G.; Del Confetto, S.; Eberling-Fux, N.; Descamps, C.; Cutard, T. Cure kinetics of a polysilazane system: Experimental characterization and numerical modelling. Eur. Polym. J. 2016, 76, 40-52. [CrossRef]

18. Mueller, S.; De Hazan, Y.; Penner, D. Effect of temperature, humidity and aminoalkoxysilane additive on the low temperature curing of polyorganosilazane coatings studied by IR spectroscopy, gravimetric and evolved gas analysis. Prog. Org. Coat. 2016, 97, 133-145. [CrossRef]

19. Kong, J.; Fan, X.; Zhang, G.; Xie, X.; Si, Q.; Wang, S. Synthesis and UV-curing behaviours of novel rapid UV-curable polyorganosilazanes. Polymer 2006, 47, 1519-1525. [CrossRef]

20. Vu, C.; Osterod, F.; Brand, S.; Ryan, K. Silicon and nitrogen. Eur. Coat. J. 2008, 38, 1-11.

21. Amouzou, D.; Fourdrinier, L.; Maseri, F.; Sporken, R. Formation of Me-O-Si covalent bonds at the interface between polysilazane and stainless steel. Appl. Surf. Sci. 2014, 320, 519-523. [CrossRef]

22. Kroke, E.; Li, Y.L.; Konetschny, C.; Lecomte, E.; Fasel, C.; Riedel, R. Silazane derived ceramics and related materials. Mater. Sci. Eng. 2000, 26, 97-199. [CrossRef]

23. Bernardo, E.; Fiocco, L.; Parcianello, G.; Storti, E.; Colombo, P. Advanced ceramics from preceramic polymers modified at the nano-scale: A review. Materials 2014, 7, 1927-1956. [CrossRef] [PubMed]

24. Barroso, G.S.; Krenkel, W.; Motz, G. Low thermal conductivity coating system for application up to $1000^{\circ} \mathrm{C}$ by simple PDC processing with active and passive fillers. J. Eur. Ceram. Soc. 2015, 35, 3339-3348. [CrossRef]

25. Lenz Leite, M.; Barroso, G.; Parchovianský, M.; Galusek, D.; Ionescu, E.; Krenkel, W.; Motz, G. Synthesis and characterization of yttrium and ytterbium silicates from their oxides and an oligosilazane by the PDC route for coating applications to protect $\mathrm{Si}_{3} \mathrm{~N}_{4}$ in hot gas environments. J. Eur. Ceram. Soc. 2017, 37, 5177-5191. [CrossRef]

26. Song, Y.C.; Zhao, Y.; Feng, C.X.; Lu, Y. Synthesis and pyrolysis of polysilazane as the precursor of $\mathrm{Si}_{3} \mathrm{~N}_{4} / \mathrm{SiC}$ ceramic. J. Mater. Sci. 1994, 29, 5745-5756. [CrossRef]

27. Kubo, T.; Tadaoka, E.; Kozuka, H. Preparation of hot water-resistant silica thin films from polysilazane solution at room temperature. J. Sol Gel Sci. Technol. 2004, 31, 257-261. [CrossRef]

28. Lu, Y.; Feng, C.X.; Song, Y.C. Curing polysilazane fibres by exposure to boron trichloride. J. Mater. Sci. Lett. 1998, 17, 481-484. [CrossRef]

29. Lukacs, A.; Knasiak, G.J. Thermally Stable, Moisture Curable Polysilazanes and Polysiloxazanes. U.S. Patent US 6,652,978 B2, 25 November 2003.

30. Furtat, P.; Lenz-Leite, M.; Ionescu, E.; Machado, R.A.F.; Motz, G. Synthesis of fluorine-modified polysilazanes: Via Si-H bond activation and their application as protective hydrophobic coatings. J. Mater. Chem. A 2017, 5, 25509-25521. [CrossRef]

31. Akutsu, K.; Niizeki, T.; Nagayama, S.; Miyata, N.; Sahara, M.; Shimomura, A.; Yoshii, M.; Hasegawa, Y. Investigation of structure of a thin $\mathrm{SiO}_{2}$ layer as an antifouling and corrosion-resistant coating. J. Ceram. Soc. Jpn. 2016, 124, 172-176. [CrossRef]

32. Augustinho, T.R.; Motz, G.; Ihlow, S.; Machado, R.A.F. Application of hybrid organic/inorganic polymers as coatings on metallic substrates. Mater. Res. Exp. 2016, 3, 095301. [CrossRef]

33. Marceaux, S.; Bressy, C.; Perrin, F.X.; Martin, C.; Margaillan, A. Development of polyorganosilazane-silicone marine coatings. Prog. Org. Coat. 2014, 77, 1919-1928. [CrossRef] 
34. Chen, Z.; Li, G.; Wang, L.; Lin, Y.; Zhou, W. A strategy for constructing superhydrophobic multilayer coatings with self-cleaning properties and mechanical durability based on the anchoring effect of organopolysilazane. Mater. Des. 2018, 141, 37-47. [CrossRef]

35. Fedel, M.; Rossi, S.; Deflorian, F. Polymethyl (hydro)/polydimethylsilazane-derived coatings applied on AA1050: Effect of the dilution in butyl acetate on the structural and electrochemical properties. J. Coat. Technol. Res. 2019, 16, 1013-1019. [CrossRef]

36. Rossi, S.; Deflorian, F.; Fedel, M. Polysilazane-based coatings: Corrosion protection and anti-graffiti properties. Surf. Eng. 2019, 35, 343-350. [CrossRef]

37. Landau, L.; Levich, V. Dragging of liquid by a moving plate. Acta Physicochim. 1942, 17, 42-54.

38. Al-Oweini, R.; El-Rassy, H. Synthesis and characterization by FTIR spectroscopy of silica aerogels prepared using several $\mathrm{Si}(\mathrm{OR})_{4}$ and $\mathrm{R}^{\prime \prime} \mathrm{Si}\left(\mathrm{OR}^{\prime}\right)_{3}$ precursors. J. Mol. Struct. 2009, 919, 140-145. [CrossRef]

39. Fedel, M.; Callone, E.; Fabbian, M.; Deflorian, F.; Dirè, S. Influence of $\mathrm{Ce}^{3+}$ doping on molecular organization of Si-based organic/inorganic sol-gel layers for corrosion protection. Appl. Surf. Sci. 2017, 414, 82-91. [CrossRef]

40. Schiavon, M.A.; Ciuffi, K.J.; Valéria, I.; Yoshida, P. Glasses in the Si-O-C-N system produced by pyrolysis of polycyclic silazane/siloxane networks. J. Non Cryst. Solids 2007, 353, 2280-2288. [CrossRef]

41. Fedel, M.; Callone, E.; Diré, S.; Deflorian, F.; Olivier, M.G.; Poelman, M. Effect of Na-Montmorillonite sonication on the protective properties of hybrid silica coatings. Electrochim. Acta 2014, 124, 90-99. [CrossRef]

42. Seo, Y.; Cho, S.; Kim, S.; Choi, S.; Kim, H. Synthesis of refractive index tunable silazane networks for transparent glass fiber reinforced composite. Ceram. Int. 2017, 43, 7895-7900. [CrossRef]

43. Schiavon, M.A.; Sorarù, G.D.; Yoshida, I.V.P. Synthesis of a polycyclic silazane network and its evolution to silicon carbonitride glass. J. Non Cryst. Solids 2002, 304, 76-83. [CrossRef]

44. Chico, B.; Galván, J.C.; de la Fuente, D.; Morcillo, M. Electrochemical impedance spectroscopy study of the effect of curing time on the early barrier properties of silane systems applied on steel substrates. Prog. Org. Coat. 2007, 60, 45-53. [CrossRef]

45. Wang, H.; Akid, R. Encapsulated cerium nitrate inhibitors to provide high-performance anti-corrosion sol-gel coatings on mild steel. Corros. Sci. 2008, 50, 1142-1148. [CrossRef]

46. Asadi, N.; Naderi, R.; Saremi, M. Determination of optimum concentration of cloisite in an eco-friendly silane sol-gel film to improve corrosion resistance of mild steel. Appl. Clay Sci. 2014, 95, 243-251. [CrossRef]

47. Pepe, A.; Galliano, P.; Aparicio, M.; Duràn, A.; Ceré, S. Sol-gel coatings on carbon steel: Electrochemical evaluation. Surf. Coat. Technol. 2006, 200, 3486-3491. [CrossRef]

48. Kirtay, S. Preparation of hybrid silica sol-gel coatings on mild steel surfaces and evaluation of their corrosion resistance. Prog. Org. Coat. 2014, 77, 1861-1866. [CrossRef]

49. Eduok, U.; Suleiman, R.; Khaled, M.; Akid, R. Enhancing water repellency and anticorrosion properties of a hybrid silica coating on mild steel. Prog. Org. Coat. 2016, 93, 97-108. [CrossRef]

50. Alinejad, S.; Naderi, R.; Mahdavian, M. The effect of zinc cation on the anticorrosion behavior of aneco-friendly silane sol-gel coating applied on mild steel. Prog. Org. Coat. 2016, 101, 142-148. [CrossRef]

51. Alibakhshi, E.; Akbarian, M.; Ramezanzadeh, M.; Ramezanzadeh, B.; Mahdavian, M. Evaluation of the corrosion protection performance of mild steel coated with hybrid sol-gel silane coating in $3.5 \mathrm{wt} . \% \mathrm{NaCl}$ solution. Prog. Org. Coat. 2018, 123, 190-200. [CrossRef]

52. Izadi, M.; Shahrabi, T.; Ramezanzadeh, B. Electrochemical investigations of the corrosion resistance of a hybrid sol-gel film containing green corrosion inhibitor-encapsulated nanocontainers. J. Taiwan Inst. Chem. Eng. 2017, 81, 356-372. [CrossRef]

53. Chawada, G.; Dholakiya, B.Z. Organic-inorganic hybrid sol-gel pretreatments for corrosion protection of mild steel in neutral and acidic solutions. Res. Chem. Intermed. 2015, 41, 3659-3674. [CrossRef]

(C) 2019 by the authors. Licensee MDPI, Basel, Switzerland. This article is an open access article distributed under the terms and conditions of the Creative Commons Attribution (CC BY) license (http://creativecommons.org/licenses/by/4.0/). 